\title{
ANÁLISE DE IMPLEMENTAÇÃO DE FERRAMENTAS DO LEAN MANUFACTURING EM UMA LANCHONETE
}

Vinícius de Almeida Silva (UFPE-CAA) va42407@gmail.com

Maria Vitória Alves de Oliveira Silva (ASCES-UNITA) mariavitoria2606@ hotmail.com Antonio Romão Alves da Silva Filho (ASCES-UNITA) romaoarasf@ gmail.com

\section{Resumo}

A filosofia de gestão Lean inspirada no Sistema Toyota, aplicável em qualquer setor e tipo de trabalho, é uma grande aliada na busca de robustez e agilidade dos processos, trabalhadores motivados e redução de custos. O objetivo do estudo é implantar duas ferramentas do Lean, o $5 \mathrm{~S}$ e o Kanban, numa lanchonete localizada em Altinho-PE. Mediante a observação do ambiente da empresa e entrevista com os colaboradores, foi feito um diagnóstico acerca de suas dificuldades, seguido pelo planejamento e implantação do 5S e Kanban. A implantação foi efetuada a partir da adaptação dos conceitos a realidade da empresa, sobre o $5 \mathrm{~S}$ foram desenvolvidos cincos sensos de qualidade para o processo e o kanban com o uso de cartões onde o cliente define o ritmo de trabalho. As ações tomadas possibilitaram para a empresa uma melhor qualidade de atendimento ao cliente, uso inteligente do espaço e gestão de estoque eficiente. Conclui-se que as melhorias aplicadas no ambiente de trabalho atingiram os colaboradores e clientes, e promoveram custos mais competitivos.

Palavras-Chaves: Instalações industriais, Just in Time, 5S, Lean Manufacturing. 


\section{Introdução}

Por volta dos anos 1900 a produção de carros ainda era artesanal, sendo feitos sob medida, segundo a vontade do dono e a preços altíssimos. Nessa época Taylor cria a engenharia industrial, a partir disso o trabalho deixa de ser empírico e passa a ser planejado para atingir a máxima produtividade, através do estudo do tempo e movimento, e deixando as atividades manuais repetitivas para os funcionários sem capacitação. Um certo tempo depois Ford desenha o primeiro automóvel com condições para ser fabricado em massa devido à maior facilidade de fabricação e conserto. Houve a padronização do uso de peças, o projeto do automóvel tornou-se mais simples (DENNIS, 2008).

Outras revoluções de Ford foram o fornecimento de peças diretamente ao funcionário, sem necessidade de deslocamento e a introdução da linha de montagem. Logo após o começo da produção em larga escala começaram a surgir problemas, como: a insatisfação do trabalhador com o trabalho repetitivo por longas horas; a qualidade, que foi bastante prejudicada pela produção em lotes, onde não era possível parar a linha de produção para reparos e isso acarretava em lotes inteiros com o mesmo defeito; e comunicação ineficiente entre os engenheiros devido a especialização em áreas distintas (DENNIS, 2008).

Seguindo o modelo de empresas já consolidadas, a Toyota (empresa japonesa de carros), lutava para crescer e então fez um acordo com seus funcionários para receberem emprego vitalício e pagamento por tempo de empresa, em troca de serem menos resistentes a mudanças na forma de produção, apoiar e trabalhar pela melhoria contínua. Com isso o trabalhador virou peça chave para a produtividade e redução de desperdícios, marcando o nascimento do Lean (DENNIS, 2008).

A produção enxuta (Lean Manufacturing), sai ganhando para a produção em massa pela maior qualidade e produtividade, além de ser possível produzir com maior variedade, com menos recursos e maior integração com a tecnologia (WOMACK; JONES e ROOS, 1990).

Foco do sistema Lean de produção, o consumidor, está cada vez mais sendo beneficiado pela competitividade das empresas, onde é oferecida uma imensa variedade de escolhas, com qualidade e preço razoável. Sendo assim o grande desafio para atingir competitividade atualmente, é reduzir custos (DENNIS, 2008).

O presente artigo tem o objetivo de fazer uma análise sobre a implantação do Lean Manufacturing em uma lanchonete localizada em Altinho-PE, focando em duas ferramentas da metodologia Lean. 
Os fatores que motivaram a elaboração deste artigo, foram: a necessidade de melhorar a qualidade do atendimento ao público, otimizar a configuração do ambiente, avaliar a instalação de novos equipamentos, melhorar a satisfação dos colaboradores com o trabalho e ter um maior controle de estoque para diminuir perdas.

\section{Fundamentação teórica}

\subsection{Lean manufacturing}

Num mercado cada vez mais competitivo, é necessário que as empresas apostem na melhoria dos seus processos produtivos com o objetivo de responder de forma mais rápida e eficaz às necessidades do mercado, mantendo a qualidade dos produtos, e baixando o custo dos mesmos (ALVES, 2007). O grande desafio das indústrias atualmente é produzir de maneira mais rápida de modo que não afete a qualidade do produto final.

Atualmente existem diversos métodos que podem auxiliar na melhoria dos sistemas de produção, as ferramentas do lean manufacturing são alguns desses métodos e elas são implantadas com o objetivo de eliminar os desperdícios e consequentemente baixar os custos de produção. São considerados como desperdícios todas as tarefas que não acrescentam valor ao produto para o cliente (ORTIZ, 2006).

O Lean Manufacturing surgiu na década de 50, no Japão, como uma filosofia de gestão que prioriza a melhoria do processo, através da eliminação contínua e sistemática das perdas do sistema produtivo. A teoria Lean Manufacturing foi criada com base no "Sistema Toyota de Produção", sistema este que surgiu dentro da Toyota, devido à persistência dos japoneses no combate ao desperdício onde buscaram novos meios para organizar o seu sistema produtivo, além da diferença de consumo do mercado japonês, se comparado com o norte-americano. Apesar da filosofia lean ter sido baseada no setor automobilístico, nos dias atuais ela é aplicada em diversos tipos de indústria. (SIQUEIRA e CAMARGO, 2018).

O Lean Manufacturing visa a eliminação de desperdícios e constante aprimoramento na agregação de valor para o cliente, atualmente, ele pode ser definido de diversas maneiras. De acordo com Shah e Ward (2002), a abordagem do lean manufacturing abrange uma ampla variedade de práticas gerenciais, como os sistemas de qualidade, o just in time, entre outros. Afirmam também que um ponto fundamental do lean manufacturing é que essas práticas devem trabalhar de maneira sinérgica para criar um sistema de alta qualidade que fabrica produtos no ritmo que o cliente deseja, sem desperdícios e mantendo a qualidade planejada. 
Já Womack e Jones (1998), por exemplo, definem o lean manufacturing como a busca por uma forma melhor de gerenciar os relacionamentos de uma empresa com seus clientes, ou seja, organizar por exemplo, a cadeia de fornecedores, o desenvolvimento de produtos e operações de produção, tendo como objetivo fazer cada vez mais, com menos.

As ferramentas do Lean que serão utilizadas nesse projeto são: o Just in time e o 5S. O JIT teve sua origem no Japão, e de maneira sucinta, significa que cada processo deve ser feito com os materiais e quantidades certas, no tempo e lugar certo. O 5s também surgiu no Japão em meados do século XX e é baseado no empenho das pessoas quanto a organização do local de trabalho por meio de manutenção apenas do necessário, da limpeza, da padronização e da disciplina na realização do trabalho, com o mínimo de supervisão possível.

\subsection{Just in time (JIT)}

O just-in-time (JIT), simboliza a busca pelo fluxo de produção, onde o objetivo é o estoque zero; mais do que isso o JIT, significa produzir o que é solicitado, no momento necessário e na quantidade pedida. Ataca ativamente o muda (desperdício), irregularidades e irracionalidades; para isso utiliza-se o kanban e o nivelamento da produção. O kanban é um instrumento que utiliza cartões de sinalização para orientar o manuseio e a produção, são eles: kanban de retirada, kanban de movimentação, kanban de produção e kanban e solicitação. O nivelamento da produção consiste em impedir que haja flutuações no fluxo do produto, ou seja significa evitar produzir em lote quando há uma demanda maior e continuar produzindo um após o outro, pois essa medida garante que os funcionários trabalhem continuamente ao invés de ficarem sobrecarregados quando há um pico de demanda e ociosos quando a demanda cai (OHNO, 1978).

De acordo com Rodrigues (2015) o just in time (JIT), teve como visionário Kiichiro Toyoda sua tradução significa "no momento exato", essa ferramenta foi inicialmente pensada para redução de desperdícios. Ela tem como objetivo nortear a organização para um menor lead time, reduzir custos, aumentar a flexibilidade, ou seja, otimizar a empresa em diversos setores.

Ainda segundo Rodrigues (2015) o JIT pode ser compreendido melhor buscando o entendimento de seus princípios e objetivos que perseguem a melhoria contínua dos processos a partir da busca de:

- Ambiente de trabalho limpo e organizado;

- Células de produção com base na tecnologia de grupo;

- Sistema à prova de falhas humanas; 
- Sistemas e equipamentos controlados pelo operador;

- Menor tempo de preparação da máquina;

- Maior integração operador x máquina;

- Sistema de produção puxada pelo cliente;

- Zero estoque em todo o processo;

- Um eficaz abastecimento e otimização da relação com os fornecedores ou parceiros;

- Zero defeito;

- Zero desperdício;

- Qualidade total.

\subsection{S}

O 5S é um sistema baseado em separar, classificar, limpar (e inspecionar), padronizar e manter. Contribui muito para o aumento da produção, organização da fábrica e motivação dos funcionários. Estabelece um local de trabalho limpo, cada objeto tem seu devido lugar e a fábrica conversa com o colaborador. Na prática os benefícios da implantação são: layout mais inteligente, itens indispensáveis sempre à mão, otimização do espaço disponível, minimização de movimentos desperdiçados, situações fora do padrão facilmente perceptíveis, padronização do trabalho e treinamento dos colaboradores (DENNIS, 2008).

Os 5S são derivados de palavras japonesas, iniciadas pela letra "S" e que exprimem princípios fundamentais da organização. SEIRI, SEITON, SEISO, SEIKETSU e SHITSUKE. Segundo Lapa (1998), os cinco primeiros "S" são definidos conforme definição abaixo:

1.SEIRI - Senso de utilização, arrumação, organização, seleção;

Seu objetivo é tornar o ambiente mais útil e menos poluído, tanto de forma visual, quanto espacial. O resultado desse primeiro passo é um ambiente de trabalho estruturado e organizado de acordo com as principais necessidades de cada empresa.

2.SEITON - Senso de ordenação, sistematização, classificação;

Busca a simplificação. Essa etapa tem como objetivo dar aos objetos que são menos utilizados um local em que eles fiquem organizados e etiquetados. E o resultado esperado é que se agilizam os processos e há maior economia de tempo. 
3.SEISO- Senso de limpeza, zelo;

Consiste na limpeza e investigação do local de trabalho em busca de rotinas que geram qualquer imperfeição. O principal resultado é um ambiente que gera satisfação nos funcionários, além de equipamentos com menos possibilidades de falhas.

4.SEIKETSU - Senso de asseio, higiene, saúde, integridade;

Consiste na manutenção das três etapas iniciais, gerando melhorias constantes para o ambiente de trabalho. O resultado é a satisfação e melhor desempenho dos funcionários contribuindo ainda mais para o andamento do processo rumo à qualidade total.

5.SHITSUKE - Senso de autodisciplina, educação, compromisso.

Quando o último processo do programa 5S está em execução, quer dizer que o programa está em andamento perfeito. Esse processo almeja que cada um exerça seu papel para a melhoria do ambiente de trabalho sem que ninguém cobre por isso.

Monden (2011) afirma que a implantação do 5S deve partir da alta gerência, pois geralmente no tipo de implantação de processo de melhoria contínua sempre existem as incertezas quanto a eficácia do processo. Antes da implantação do $5 \mathrm{~S}$ é preciso que os colaboradores mudem seu modo de pensar e suas atitudes em relação ao trabalho.

As etapas para implantação e manutenção do $5 \mathrm{~S}$ serão apresentadas a seguir na figura 1:

Figura 1 - Etapas para implementação e manutenção do 5S 


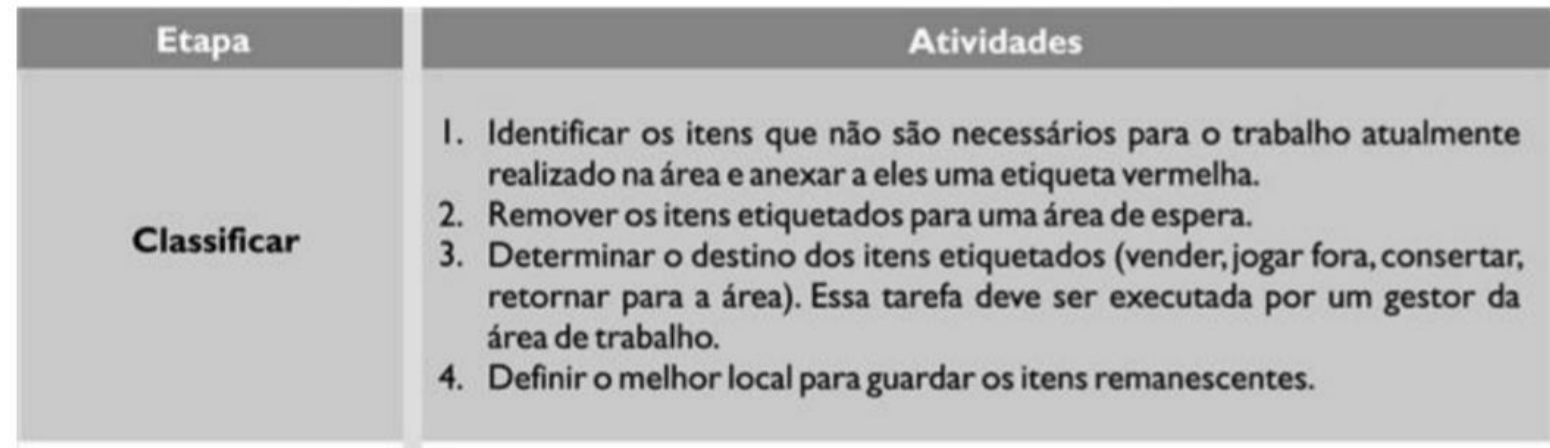

I. Identificar os itens necessários, para que os mesmos possam ser encontrados por qualquer pessoa.

2. Criar limites eáreas para colocação dos itens.

Ordenar 3. Desenhar um mapa 5S apresentando a melhor localização para cada item, com base na frequência de uso e nos princípios de economia de movimentos.

\begin{tabular}{|c|c|}
\hline Limpar & $\begin{array}{l}\text { 1. Limpar a área de trabalho. } \\
\text { 2. Criar procedimentos para a limpeza diária, de modo a manter a área de } \\
\text { trabalho arrumada e livre de entulhos. } \\
\text { 3. Atribuir tarefas de limpeza rotineiras às pessoas que operam o processo. }\end{array}$ \\
\hline Padronizar & $\begin{array}{l}\text { I. Criar procedimentos padronizados para a realização das tarefas diárias das } \\
\text { etapas classificar,ordenar e limpar. } \\
\text { 2. Afixar,na área de trabalho, fotografias do "antes" e "depois" e incorporar o } \\
\text { "depois" ao padrão. }\end{array}$ \\
\hline Manter & $\begin{array}{l}\text { I. Criar uma disciplina para o } 5 \mathrm{~S} \text {, de modo a assegurar a continuidade de seu } \\
\text { sucesso. } \\
\text { 2. Auditorar periodicamente o cumprimento dos padrões do } 5 \mathrm{~S} \text {. } \\
\text { 3. Reforçar a importância do cumprimento dos padrões, por meio do } \\
\text { reconhecimento nos casos de sucesso e da ação corretiva nas situações de } \\
\text { desvio. }\end{array}$ \\
\hline
\end{tabular}

Fonte: Werkman (2012)

\section{Procedimentos metodológicos}

A pesquisa pode ter diversas classificações, que segundo Vergara (2011), existem várias taxionomias de tipos de pesquisa, quanto aos fins e quanto aos meios.

Quanto aos fins podem ser: pesquisa exploratória, explicativa, descritiva, aplicada, intervencionista e metodológica, e quanto aos meios: pesquisa de campo, de laboratório, documental, bibliográfica, experimental, ex-post-facto, participante, pesquisa-ação e estudo de caso. E quanto aos meios, a pesquisa pode ser bibliográfica e de campo.

Diante do problema estudado, análise sobre a implantação do Lean Manufacturing em uma lanchonete localizada em Altinho-PE, focando em duas ferramentas da metodologia Lean, 
conforme a Vergara (2011) pode-se dizer que, quanto aos fins, esta é uma pesquisa exploratória e quanto aos meios é uma pesquisa de campo na forma de estudo de caso e documental, pois os dados foram coletados pelo processo de observação "in loco" com o pesquisador não participante e de forma assistemática e com os relatórios do pessoal operacional da lanchonete.

Quanto à forma de abordagem é uma pesquisa qualitativa, pois não houve preocupação com medidas, quantificações ou técnicas estatísticas de qualquer natureza (GIL, 1999). Buscase compreender, com base em dados qualificáveis, a realidade de determinados fenômenos. Nesse caso os pesquisadores atuaram como principal instrumento e os fenômenos foram estudados "in loco", sem nenhuma manipulação intencional do pesquisador.

Durante a pesquisa foram realizadas visitas para observação dos processos com o intuito de levantar dados primários. A observação foi do tipo assistemático. Os dados levantados foram utilizados para elaboração, com o auxílio de ferramentas tradicionais da Engenharia da Produção, permitindo a padronização da descrição de rotinas de informação e processos.

\section{Resultados}

\subsection{Descrição da empresa}

Fundada em 1993, com sede em Altinho-PE, iniciou suas atividades na feira livre da cidade. É uma empresa familiar que trabalha no segmento de serviço rápido de alimentação, conta com 5 colaboradores e seu principal produto comercializado é o pastel. Sua missão é a busca constante do aperfeiçoamento da qualidade dos lanches e atendimento ao público.

A lanchonete enfrenta dificuldades na gestão e nos processos produtivos do negócio, em razão do crescimento sem planejamento.

\subsection{Análise de pré-implantação do $5 \mathrm{~S}$ e JIT}

O 5S é um programa simples com baixo custo de implantação e pode ser adequado de acordo com a realidade da empresa. Com isso foi realizada uma exploração visual na cozinha da lanchonete e uma entrevista com os colaboradores, a fim de levantar problemas para correlacioná-los com a execução dos cinco sensos.

O diagnóstico deu-se num primeiro momento pela exploração visual com o objetivo de entender como funciona o processo de fabricação e perceber problemas com relação ao fluxo de movimento, a configuração do mobiliário, presença de objetos desnecessários e controles 
visuais. Num segundo momento a entrevista com os colaboradores permitiu validar problemas já observados e conhecer o ponto de vista deles em relação ao ambiente de trabalho.

Os colaboradores foram questionados durante a entrevista sobre aspectos dos sensos de utilização, organização e limpeza. As perguntas sobre o senso de utilização exploraram a presença de objetos desnecessários. Para o senso de organização procurou-se conhecer sobre o grau de dificuldade em achar materiais, a sinalização e aproveitamento do espaço, e possíveis adaptações a configuração das máquinas e móveis. Para o senso de limpeza buscou-se identificar questões quanto a percepção de limpeza, iluminação do ambiente, temperatura e manutenção das máquinas.

O resultado da investigação quanto ao senso de organização mostrou que de fato existem muitos objetos em excesso que acabam tomando espaço valioso na cozinha. A respeito do senso de utilização relataram que havia uma alta dificuldade em encontrar utensílios e insumos, ausência de sinalização, espaço estreito e necessidade de reposicionar alguns móveis. Com relação ao senso de limpeza expuseram que a percepção de limpeza no primeiro momento de trabalho é boa, mas até o fim do expediente vai diminuindo porque tudo que se suja não é limpo imediatamente; acerca da temperatura é consenso que o ambiente da cozinha é um pouco quente, principalmente em dias de calor; sobre a iluminação não houveram reclamações, todos acham que há um bom nível de claridade e por último quanto a manutenção das máquinas, relataram que não é feita com frequência.

O Kanban é um sistema de gestão visual que autoriza e fornece instruções para fabricar produtos ou deslocar itens em um sistema puxado. A partir disso a ferramenta é excelente para ser aplicada ao controle de estoque da lanchonete.

O diagnóstico inicialmente ocorreu através de exploração visual na cozinha com o propósito de verificar a quantidade de estoque na empresa e como se dava seu armazenamento. E depois por entrevista com os donos para confirmar os problemas encontrados e obter esclarecimentos sobre alguns pontos.

Ao término da apuração foi constatado que não havia nenhum tipo de controle sobre a compra de produtos, sendo eles comprados na maioria das vezes em excesso pela oferta de menor preço do fornecedor; inexistência de lugar específico para estocagem e desconhecimento do que há efetivamente no estoque, resultando em produtos vencidos antes do uso e eventual falta de produto em estoque.

\subsection{Plano de implantação do 5S e JIT}


Com base nos problemas encontrados pelo diagnóstico, foi possível conhecer melhor o estado do negócio e a partir disso propor soluções para implantar melhorias. Dessa forma procurou-se adaptar o 5S e Kanban de acordo com as considerações dos donos e funcionários. Feito isso o planejamento das intervenções do $5 \mathrm{~S}$, deu-se com plano de ação $5 \mathrm{~W} 1 \mathrm{H}$.

\subsubsection{Programa 5S}

$1^{\circ}$ Senso - Utilização

Quadro 1 - 5W1H: Senso de utilização

\begin{tabular}{|c|c|}
\hline \multicolumn{2}{|r|}{ 5W1H: $1^{\circ}$ Senso - Utilização } \\
\hline $\begin{array}{l}\text { What? } \\
\text { "O que?" }\end{array}$ & Etiquetagem vermelha \\
\hline $\begin{array}{c}\text { Why? } \\
\text { "Por que?" }\end{array}$ & Identificação de itens que serão descartados ou permanecerão no local de forma diferente. \\
\hline $\begin{array}{l}\text { Where? } \\
\text { "Onde?" }\end{array}$ & Cozinha \\
\hline $\begin{array}{l}\text { How? } \\
\text { "Como?" }\end{array}$ & $\begin{array}{l}\text { 1. Colocar etiquetas em itens desnecessários; } \\
\text { 2. Demarcação no chão de área de etiquetas vermelhas para remoção; } \\
\text { 3. Prazo de sete dias depois da etiquetagem para revisão dos itens; } \\
\text { 4. Avaliação de itens que podem ser reciclados ou vendidos; } \\
\text { 5. Definição de etiquetagem vermelha anual. }\end{array}$ \\
\hline $\begin{array}{c}\text { Who? } \\
\text { "Quem?" }\end{array}$ & Todos os colaboradores \\
\hline $\begin{array}{c}\text { When? } \\
\text { "Quando?" }\end{array}$ & Em apenas um dia com duração de até 3 horas. \\
\hline
\end{tabular}

Fonte: Autoria própria (2020)

Seguindo as recomendações do plano de ação para aplicação da etiquetagem vermelha, foi realizado um dia " $\mathrm{D}$ " com todos os colaboradores para classificar os objetos da cozinha segundo frequência de uso. A etiqueta contém as seguintes informações: classificação do item, identificação e quantidade do item, motivo para a etiquetagem vermelha, seção de trabalho e data. A avaliação dos objetos separados para descarte mostrou que eles não serviam para reciclagem ou venda. Foi definida a etiquetagem vermelha anual na primeira quinzena do mês de janeiro de cada ano. Houve também o descarte de todos os móveis de madeira, como bancadas e armários.

$2^{\circ}$ Senso - Organização

Quadro $2-5$ W1H: Senso de organização 


\begin{tabular}{|c|c|c|c|c|c|}
\hline \multicolumn{6}{|c|}{ 5W1H: $2^{\circ}$ Senso - Organização } \\
\hline $\begin{array}{l}\text { What? } \\
\text { "O que?" }\end{array}$ & $\begin{array}{c}\text { Why? } \\
\text { "Por que?" }\end{array}$ & $\begin{array}{l}\text { Where? } \\
\text { "Onde?" }\end{array}$ & $\begin{array}{l}\text { How? } \\
\text { "Como?" }\end{array}$ & $\begin{array}{c}\text { Who? } \\
\text { "Quem?" }\end{array}$ & $\begin{array}{c}\text { When? } \\
\text { "Quando?" }\end{array}$ \\
\hline $\begin{array}{l}\text { Otimização de } \\
\text { layout }\end{array}$ & \begin{tabular}{|l|} 
Minimizar \\
movimentos \\
desperdiçados
\end{tabular} & Cozinha & $\begin{array}{l}\text { Pesquisa de um } \\
\text { layout } \\
\text { adequadro para } \\
\text { a organização } \\
\text { do ambiente e } \\
\text { distribuição do } \\
\text { mobiliário. }\end{array}$ & $\begin{array}{l}\text { Anália } \\
\text { Assunção - } \\
\text { Arquiteta }\end{array}$ & $\begin{array}{l}\text { Outubro de } \\
2019\end{array}$ \\
\hline $\begin{array}{l}\text { Instalação de } \\
\text { novos } \\
\text { equipamentos }\end{array}$ & $\begin{array}{l}\text { Melhoria do } \\
\text { desempenho } \\
\text { da equipe e } \\
\text { aumento da } \\
\text { produtividade }\end{array}$ & Cozinha & \begin{tabular}{|l|} 
Estabelecimento \\
de pia inox, \\
coifa, móveis de \\
alumínio e \\
instalação de \\
exaustor de \\
parede.
\end{tabular} & $\begin{array}{l}\text { Equipe } \\
\text { terceirizada }\end{array}$ & $\begin{array}{l}\text { Novembro de } \\
2019\end{array}$ \\
\hline $\begin{array}{l}\text { Criação de } \\
\text { almoxarifado }\end{array}$ & \begin{tabular}{|l|} 
Materiais \\
localizados em \\
um único \\
espaço
\end{tabular} & Lanchonete & $\begin{array}{l}\text { Anexação de } \\
\text { imóvel vizinho. }\end{array}$ & $\begin{array}{l}\text { Equipe } \\
\text { terceirizada }\end{array}$ & $\begin{array}{l}\text { Novembro de } \\
2019\end{array}$ \\
\hline $\begin{array}{l}\text { Pintura no } \\
\text { chão }\end{array}$ & $\begin{array}{l}\text { Delimitar } \\
\text { perímetros }\end{array}$ & Cozinha & \begin{tabular}{|l|} 
Pintura de \\
faixas, seguindo \\
padrão de cores \\
ANSI. \\
\end{tabular} & $\begin{array}{l}\text { Equipe } \\
\text { terceirizada }\end{array}$ & $\begin{array}{l}\text { Dezembro de } \\
2019\end{array}$ \\
\hline $\begin{array}{l}\text { Utilização de } \\
\text { painel sombra }\end{array}$ & $\begin{array}{l}\text { Organizar } \\
\text { utensilios de } \\
\text { uso frequente }\end{array}$ & Cozinha & $\begin{array}{l}\text { Encomenda de } \\
\text { painel }\end{array}$ & Marceneiro & $\begin{array}{l}\text { Dezembro de } \\
2019\end{array}$ \\
\hline
\end{tabular}

Fonte: Autoria própria (2020)

Avançando para implantação do $2^{\circ}$ senso, foi contratada uma arquiteta para deixar o layout da cozinha mais funcional; a instalação dos equipamentos foi concluída no final de abril de 2020, por ter coincidido com a crise sanitária da pandemia; sobre o almoxarifado foi aberta uma parede para conectar o espaço do imóvel vizinho à lanchonete, sendo finalizada em março de 2020; quanto à demarcação de faixas no chão e uso do painel sombra, essas etapas estão programadas para a reabertura do comércio para evitar gastos desnecessários. Ainda sobre o senso foram definidas regras de organização: 1 . Distribuição de itens por ordem de uso; 2. Se os itens forem usados juntos, guarde-os juntos; 3. Arrumação de freezer horizontal: $1^{\circ}$ Organizar por tipo: carne vai com carne, aves com aves, e assim por diante; $2^{\circ}$ Separe por tamanho: do menor para o maior; $3^{\circ}$ Uso de cestas vazadas; $4^{\circ}$ Manter lista atualizada do conteúdo do freezer.

A seguir, proposta de layout para cozinha:

Figura 2 - Proposta de layout para cozinha 


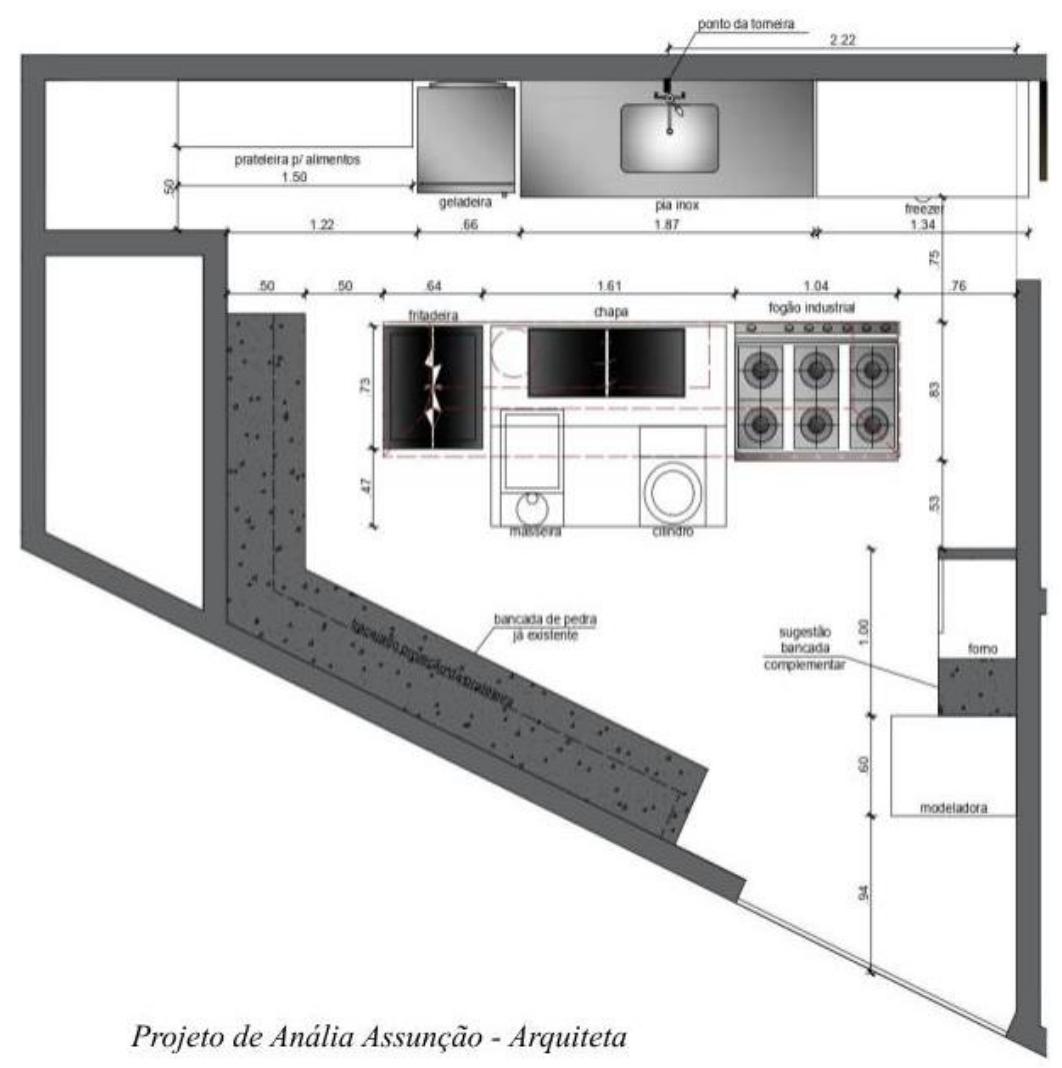

Fonte: Anália Assunção (2019)

$3^{\circ}$ Senso - Limpeza

Quadro 3 - 5W1H: Senso de limpeza 


\begin{tabular}{|c|c|c|c|c|c|}
\hline \multicolumn{6}{|c|}{ 5W1H: $3^{\circ}$ Senso - Limpeza } \\
\hline $\begin{array}{l}\text { What? } \\
\text { "O que?" }\end{array}$ & $\begin{array}{c}\text { Why? } \\
\text { "Por que?" }\end{array}$ & $\begin{array}{l}\text { Where? } \\
\text { "Onde?" }\end{array}$ & $\begin{array}{c}\text { How? } \\
\text { "Como?" }\end{array}$ & $\begin{array}{c}\text { Who? } \\
\text { "Quem?" }\end{array}$ & $\begin{array}{c}\text { When? } \\
\text { "Quando?" }\end{array}$ \\
\hline $\begin{array}{l}\text { Lista de } \\
\text { verificação de } \\
\text { limpeza }\end{array}$ & $\begin{array}{l}\text { Manter rotina } \\
\text { de limpeza }\end{array}$ & Cozinha & \begin{tabular}{|l|} 
Esquema \\
detalhado com \\
áreas que \\
devem ser \\
limpas. \\
\end{tabular} & $\begin{array}{l}\text { Revezamento } \\
\text { de } \\
\text { funcionários }\end{array}$ & Diariamente \\
\hline $\begin{array}{l}\text { Informativo } \\
\text { com } \\
\text { responsabilida } \\
\text { des e horários } \\
\text { de limpeza } \\
\end{array}$ & $\begin{array}{l}\text { Delimitar } \\
\text { tarefas }\end{array}$ & Cozinha & \begin{tabular}{|l|} 
O colaborador \\
assina seu \\
nome ao \\
término da \\
tarefa. \\
\end{tabular} & \begin{tabular}{|l|} 
Funcionário \\
designado para \\
tarefa.
\end{tabular} & Diariamente \\
\hline $\begin{array}{l}\text { Lista de } \\
\text { verificação de } \\
\text { regulariadade } \\
\text { de máquinas }\end{array}$ & Evitar quebras & Cozinha & $\begin{array}{l}\text { Identificar } \\
\text { mudanças em } \\
\text { termos de } \\
\text { som, cheiro, } \\
\text { vibração, } \\
\text { temperatura e } \\
\text { outros. }\end{array}$ & \begin{tabular}{|l|} 
Funcionário \\
designado para \\
tarefa.
\end{tabular} & 1 vez ao mês \\
\hline $\begin{array}{l}\text { Estação de } \\
\text { limpeza 5S }\end{array}$ & \begin{tabular}{|l|} 
Local central \\
para \\
ferramentas de \\
limpeza. \\
Mostra que a \\
empresa leva a \\
higiene a \\
sério. \\
\end{tabular} & Cozinha & \begin{tabular}{|l|} 
Vassoura, pá \\
de lixo, \\
escova, \\
esfregão e \\
balde, um saco \\
de panos de \\
limpeza e \\
lixeira. \\
\end{tabular} & $\begin{array}{l}\text { Placa de } \\
\text { sombra em } \\
\text { estrutura de } \\
\text { aço com } \\
\text { rodinhas. }\end{array}$ & \\
\hline
\end{tabular}

Fonte: Autoria própria (2020)

Prosseguindo para o senso de limpeza, a checklist de faxina e o informativo com as responsabilidades e horários foram colocados próximo à entrada da cozinha; adoção da regra de limpeza de um minuto: ao sujar, limpe imediatamente; limpeza geral da lanchonete, 30 min antes do final do expediente; checklist mensal para verificar a regularidade de máquinas e ferramentas; sobre a estação 5S de limpeza, está em processo de aquisição.

\section{$4^{\circ}$ Senso - Padronização}

Normas apresentadas:

Padrões do senso de utilização (etiquetagem vermelha):

1. Os itens inúteis são alvo da etiquetagem vermelha; a qual deve ser realizada uma vez por ano e respeitado o prazo de 7 dias para revisar o descarte ou não de algum item.

2. Analisar se os objetos selecionados para o descarte, podem ser vendidos ou reciclados, em caso negativo direcionar para o lixo.

Padrões do senso de organização 
1. Os documentos e avisos, devem ser colocados próximo a entrada da cozinha.

2. Dentro das linhas marcadas no piso apenas elementos já estabelecidos. É permitido caminhar apenas no espaço livre entre as linhas.

3. Cada funcionário deve estar usando: boné e/ou touca, camisa da empresa, calça sem rasgões e sapato fechado.

Padrões de limpeza:

1. Todas as bancadas, utensílios, máquinas e o chão devem ser limpos regularmente. A inspeção deve abranger todas as máquinas, identificando se há mudanças em termos de som, cheiro, vibração, temperatura, entre outros.

2. A limpeza deve ser feita imediatamente ao sujar qualquer coisa e uma limpeza geral 30 min antes do final do expediente. A inspeção deve ser feita brevemente em cada mês.

3. Cada colaborador é responsável por deixar o ambiente limpo de acordo com o que for definido pela empresa.

Medição das ações do 5S: Cartão com pontuação 5S para a cozinha e uma programação de verificação padronizada.

$5^{\circ}$ Senso - Disciplina

Quadro $4-5 \mathrm{~W} 1 \mathrm{H}$ : Senso de disciplina 


\begin{tabular}{|c|c|c|c|c|c|}
\hline \multicolumn{6}{|c|}{$5 \mathrm{~W} 1 \mathrm{H}: 5^{\circ}$ Senso - Disciplina } \\
\hline $\begin{array}{l}\text { What? } \\
\text { "O que?" }\end{array}$ & $\begin{array}{c}\text { Why? } \\
\text { "Por que?" }\end{array}$ & $\begin{array}{l}\text { Where? } \\
\text { "Onde?" }\end{array}$ & $\begin{array}{l}\text { How? } \\
\text { "Como?" }\end{array}$ & $\begin{array}{l}\text { Who? } \\
\text { "Quem?" }\end{array}$ & $\begin{array}{c}\text { When? } \\
\text { "Quando?" }\end{array}$ \\
\hline $\begin{array}{l}\text { Quadro } \\
\text { informativo }\end{array}$ & $\begin{array}{l}\text { Maior } \\
\text { envolvimento da } \\
\text { equipe }\end{array}$ & Cozinha & $\begin{array}{l}\text { Objetivos e o } \\
\text { estado atual do } \\
5 \mathrm{~S} \text {, a grande } \\
\text { melhoria do } \\
\text { mês e fotos de } \\
\text { antes e depois. }\end{array}$ & $\begin{array}{l}\text { Todos os } \\
\text { colaboradores }\end{array}$ & Mensalmente \\
\hline Premiação & $\begin{array}{l}\text { Maior } \\
\text { engajamento dos } \\
\text { funcionários e } \\
\text { reconhecimento }\end{array}$ & Cozinha & $\begin{array}{l}\text { Sugestões: } \\
\text { pequenas } \\
\text { festas, } \\
\text { bonificação } \\
\text { em dinheiro, } \\
\text { curso de } \\
\text { idioma ou } \\
\text { profissionaliza } \\
\text { nte, ingressos } \\
\text { para shows e } \\
\text { atividades, dia } \\
\text { de folga, entre } \\
\text { outros. }\end{array}$ & $\begin{array}{l}\text { Funcionário } \\
\text { que apresentar } \\
\text { melhoria } \\
\text { significativa. }\end{array}$ & Mensalmente \\
\hline Auditoria & $\begin{array}{l}\text { Fortalecer a } \\
\text { prática de bons } \\
\text { hábitos }\end{array}$ & Cozinha & $\begin{array}{l}\text { Comparar o } \\
\text { estado atual } \\
\text { com base em } \\
\text { fotos de } \\
\text { referência. }\end{array}$ & $\begin{array}{l}\text { Funcionário } \\
\text { designado para } \\
\text { tarefa. }\end{array}$ & Semanal \\
\hline
\end{tabular}

Fonte: Autoria própria (2020)

Finalizando a implantação do 5S, foram recomendadas duas ações de comprometimento: quadro informativo e premiação. A auditoria analisa os padrões de organização com base em fotos de referência, como no exemplo a seguir:

Figura 3 - Organização anterior e atual

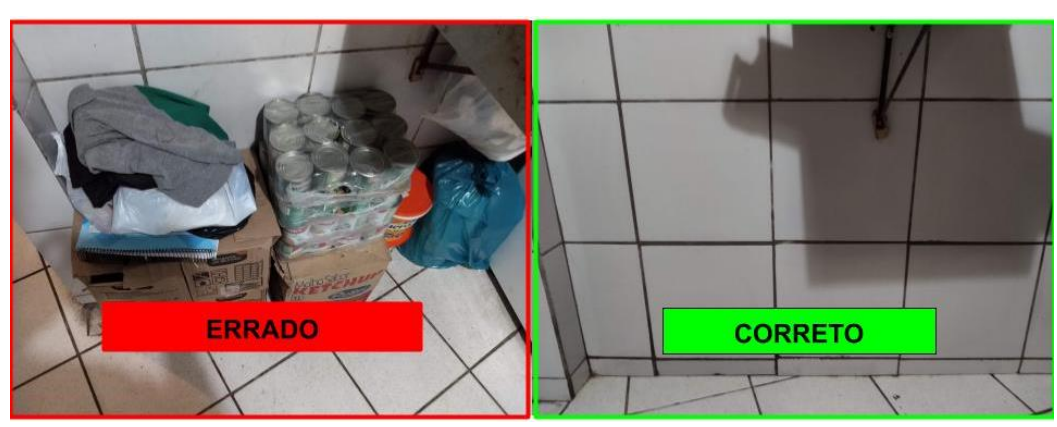

Fonte: Autoria própria (2020)

\subsubsection{Just in time}

Sobre o JIT, a ferramenta utilizada para implantação foi o Kanban. Um kanban é um cartão que representa uma autorização para produzir ou parar. Trabalhando com o kanban de produção e o kanban de retirada, o processo de implantação na lanchonete foi pensado para o sistema puxado, que significa não fazer nada se ninguém solicita. 
Quadro 5 - Execução do Kanban

\begin{tabular}{|l|}
\hline \multicolumn{1}{|c|}{ Aplicação do Kanban no processo produtivo de pastel } \\
\hline \multicolumn{1}{|c|}{ Etapas: } \\
\hline $\begin{array}{l}\text { 1. Começando com } 5 \text { unidades de cada sabor, separadas por } \\
\text { bandejas, de modo que cada bandeja tenha um kanban de } \\
\text { produção. }\end{array}$ \\
\hline $\begin{array}{l}\text { 2. Quando os clientes solicitarem mais de } 5 \text { unidades de } \\
\text { determinado sabor, é emitido um Kanban de produção, } \\
\text { especificando o tipo de recheio e quantidade de pastéis a ser } \\
\text { produzida. }\end{array}$ \\
\hline $\begin{array}{l}\text { 3. Ao usar material para atender o kanban de produção, é } \\
\text { gerado um kanban de retirada de material. }\end{array}$ \\
\hline $\begin{array}{l}\text { 4. Esse kanban de retirada é depositado num painel e sinaliza a } \\
\text { necessidade de ressuprimento ao atingir pontos pré-definidos. }\end{array}$ \\
\hline $\begin{array}{l}\text { 5. A partir das informações dos cartões de retirada, é solicitado } \\
\text { ao fornecedor a quantidade de itens que foi retirado do estoque. }\end{array}$ \\
\hline
\end{tabular}

Fonte: Autoria própria (2020)

O cumprimento das ações planejadas para o Kanban, ainda está em andamento por causa da estruturação do almoxarifado e diminuição da demanda devido a pandemia. Contudo espera-se que brevemente a lanchonete será capaz de ter maior agilidade na entrega do produto final, diminuição de falhas e otimização da armazenagem, através da adoção de estoque mínimo.

\section{Considerações finais}

Com base no artigo apresentado, foi possível analisar o quanto a implantação do Lean Manufacturing trouxe melhorias, não apenas para o local de trabalho da lanchonete como também para os colaboradores e clientes. Através do 5S, foi observada uma grande mudança no ambiente de trabalho em diversos setores, como na parte das instalações de novos equipamentos, na limpeza do local, na organização de utensílios necessários e desnecessários, na estocagem, entre outros. Já na implantação do JIT, a ferramenta que mais se adequou ao projeto descrito foi o Kanban, pois ajuda a viabilizar a produção puxada que reduz de forma drástica os estoques intermediários entre processos. Ademais, foi notório que apesar do sistema Lean ser antigo, suas aplicações funcionam perfeitamente atualmente e em qualquer tipo de organização, basta adequá-lo.

\section{Referências}


ALVES, A. C. (2007). Projeto dinâmico de Sistemas de Produção Orientados ao

Produto. Tese de Doutoramento em Engenharia e Produção de Sistemas. Escola de Engenharia. Universidade do Minho.

CAMPOS, R. et al. A ferramenta $5 \mathrm{~S}$ e suas implicações na gestão da qualidade total.

Simep - Simpósio de Engenharia de Produção, v. 12, p. 685-692, 2005.

DENNIS, P. Produção Lean Simplificada. 2. ed. Porto Alegre: Bookman, 2008.

Monografia (Graduação) - Programa de Graduação em Engenharia de Produção,

Universidade Federal de Juiz de Fora.

GIL, A. C. Métodos e técnicas de pesquisa social. São Paulo: Atlas, 1999.

LAPA, R. P. Programa 5S; Rio de Janeiro: Qualitymark, 1998.

MARTINS, P; BIDIN, L. O sistema Just in Time: uma visão crítica de sua

implementação. SIMPEP, 2006. Disponível em:

<https://simpep.feb.unesp.br/anais/anais_13/artigos/1149.pdf>. Acesso em 7 de mai. 2020.

MONDEN, Y. Sistema de produção Toyota: uma abordagem integrada ao just-in-time.

CRc Press, 2011.

OHNO, T. O Sistema Toyota de Produção. Além da Produção em Larga Escala. Bookman, 1997.

ORTIZ, C. A. (2006). Kaizen Assembly: Designing, Constructing, and Managing a Lean Assembly Line. New York: CRC Press.

RIANI, A. M. (2006). Estudo de caso: o lean manufacturing aplicado na Becton

Dickinson. RODRIGUES, M. V. (2015). Entendendo, aprendendo e desenvolvendo sistemas de produção Lean Manufacturing. Elsevier Brasil.

SHAH, R.; WARD, P.T. Lean manufacturing: context, practice bundles, and performance. J. Oper. Manag., v.335, p.1-21, 2002.

VERGARA, S. C. Projetos e Relatórios de Pesquisa em Administração. São Paulo: Atlas, 2011.

WERKEMA, C. Lean seis sigma: Introdução às Ferramentas do Lean Manufacturing. 2. ed. Rio de Janeiro: Elsevier, 2012.

WOMACK, J; JONES, D; ROOS, D. A Máquina que Mudou o Mundo. 10. ed. Rio de Janeiro: Elsevier, 2004. 